\title{
LA UTILIZACIÓN DE LA CÁMARA OCULTA EN EL PERIODISMO DE INVESTIGACIÓN: ¿EL FIN JUSTIFICA LOS MEDIOS?
}

\author{
ANTONIO MAGDALENO ALEGRÍA \\ Profesor Contratado Doctor de Derecho Constitucional \\ Universidad de Cantabria
}

SUMARIO.-

Introducción.

I. El derecho a investigar como parte del contenido constitucionalmente protegido de la libertad de información.

II. Los derechos a la intimidad personal y familiar y a la propia imagen.

III. La ponderación como instrumento para la resolución de conflictos entre los derechos fundamentales.

IV. Aplicación de los criterios de ponderación a los reportajes realizados mediante cámara oculta.

\section{INTRODUCCIÓN}

En muchas ocasiones, la vulneración de un derecho fundamental no proviene de la acción de un poder público, sino que se ocasiona por sujetos particulares o entes privados. Así, por ejemplo, la gran mayoría de las intromisiones en los derechos de la personalidad consagrados en el artículo 18 de la CE tienen origen en el ejercicio de las libertades de comunicación pública por parte sujetos privados; normalmente por profesionales de la información a través de los medios de comunicación, aunque lo cierto es que se está produciendo un importante aumento de vulneraciones procedentes de sujetos particulares, gracias a las posibilidades que les confieren las nuevas tecnologías de la comunicación, especialmente las redes sociales ${ }^{1}$. Sobre la cuestión, existe un importante corpus jurispru- 
dencial que se centra esencialmente en el contenido del mensaje, esto es, qué difusiones de ideas, opiniones o sentimientos (libertad de expresión) o de hechos (libertad de información) suponen una intromisión injustificada en los derechos al honor, a la intimidad personal y familiar y a la propia imagen. Por el contrario, hasta el presente momento, no existía ningún pronunciamiento en sede constitucional sobre las concretas técnicas o métodos de obtención de la información ${ }^{2}$, en particular, sobre la posibilidad de utilizar la cámara oculta.

Es controvertida la utilización de determinados métodos para la obtención de información, pues algunos medios de comunicación, en ocasiones, acuden a determinadas técnicas, cuanto menos discutibles. Así, sobre un determinado grupo mediático de carácter sensacionalista en el Reino Unido pesa la acusación de obtener información a través de medios ilícitos como, por ejemplo, mediante la interceptación de las comunicaciones $^{3}$. En nuestro país, los métodos de obtención de la información por parte de los periodistas han cobrado interés como consecuencia de que la STC 12/2012 ha determinado la prohibición constitucional del uso de la cámara oculta ${ }^{4}$.

Pues bien, en el presente estudio se analizará desde una perspectiva constitucional y, por ende, desde la dogmática de los derechos fundamentales, la adecuación al marco constitucional de la citada técnica de investigación periodística. Para ello, se delimitará, en primer lugar, el contenido constitucionalmente protegido de la libertad de información, esto es, cuáles son las conductas que, en principio, se encuentran protegidas por el artículo 20 de la CE, prestando especial interés a la fase de obtención de la información. De la misma manera, y en segundo lugar, se delimitarán los derechos susceptibles de ser afectados por la utilización de la cámara oculta, es decir, los derechos fundamentales a la intimidad personal y familiar y a la propia imagen 5 . Una vez delimitados los citados derechos, en tercer lugar se analizará el método constitucionalmente adecuado para la resolución de los conflictos entre los derechos fundamentales, esto es, el método de ponderación. Y, por último, se analizará el caso recientemente resuelto por el TC sobre la utilización de la cámara oculta.

1 Se trata de una cuestión que está despertando un importante interés en la doctrina. Entre otros, véanse COTINO HUESO, L. (Coord.): Libertad en Internet. La red y las libertades de expresión e información, Valencia, Tirant lo Blanch, 2007, COTINO HUESO, L. (Ed.).: Libertades de expresión e información en Internet: ejercicio, amenazas y garantías, Valencia, PUV, 2011; ROIG, A.: Derechos fundamentales y tecnologías de la información y de las comunicaciones, Barcelona, Boch, 2010.

2 Sí, por el contrario, existen algunos pronunciamientos previos en la jurisdicción ordinaria. A modo de ejemplo, entre otras, véanse STS 506/2009, de 6 de julio; STS 1233/2009, de 16 de enero; STS 336/2010, de 20 de mayo, y STS 179/2011, de 18 de marzo.

3 Sobre la obtención de información de manera ilícita en Derecho comparado, véase MEDINA GUERRERO, M.: La protección constitucional de la intimidad frente a los medios de comunicación, Valencia, Tirant lo Blanch, 2005, págs. 167 y ss.

4 Doctrina que ha sido ratificada en la STC 24/2012, de 27 de febrero y en la STC 74/2012, de 16 de abril.

5 Téngase en cuenta que en los conflictos entre los derechos fundamentales, la primera labor que se debe realizar es la identificación de los principios (bienes, valores, intereses) en juego. En este sentido, en la STC 76/1995, de 22 de mayo, FJ 5º se afirma lo siguiente: «una vez despejadas las dos incógnitas previas, que no eran sino la identificación de la libertad en juego y el contenido del derecho que le sirve de límite, el paso siguiente habrá de ser la ponderación de una y otro, sin olvidar su distinto peso específico. (...) El análisis para sopesar los derechos en tensión ha de hacerse atendiendo a las circunstancias concurrentes en cada caso».

UNED. Teoría y Realidad Constitucional, núm. 30, 2012, pp. 515-532. 
Finalmente, se quiere dejar constancia de que, si bien el presente estudio se realiza desde una perspectiva jurídica, se considera de gran interés realizar alguna referencia a lo establecido en los libros de estilo de los medios de comunicación y en los códigos deontológicos elaborados por los profesionales de la información. La citada perspectiva no sólo coadyuvará a la comprensión de la cuestión, sino que resulta obligada, pues el TEDH alude, siquiera obiter dictum, a la necesidad de tener en cuenta dichos documentos a la hora de examinar la legitimidad del método utilizado para obtener información.

\section{EL DERECHO A INVESTIGAR COMO PARTE DEL CONTENIDO CONSTITUCIONALMENTE PROTEGIDO DE LA LIBERTAD DE INFORMACIÓN}

Si bien el TC mantuvo en sus primeros pronunciamientos que la libertad de información es una modalidad de la libertad de expresión ${ }^{6}$, lo cierto es que rápidamente reconsideró su posición ${ }^{7}$, para concluir que se trata de dos libertades públicas diferentes por razón de su objeto. En efecto, mientras que la libertad de expresión protege la libre manifestación de ideas, sentimientos y opiniones que, por su naturaleza, no se encuentran sometidas a demostración de exactitud ${ }^{8}$, la libertad de información protege exclusivamente la libre transmisión y recepción de hechos veraces que, a diferencia del caso anterior, sí son susceptibles de contraste en la medida que se refieren a acontecimientos de la realidad $^{9}$. Se trata de una distinción que estuvo en el propósito del constituyente, pues reconoció las citadas libertades públicas en apartados distintos del artículo 20 de la CE y, además, a la hora de definir o delimitar dichas libertades públicas, sólo estableció el límite interno de la veracidad exclusivamente en relación a la libertad de información. En otras palabras, el requisito de la veracidad forma parte de la definición del derecho y, en consecuencia, sólo están amparadas aquellas informaciones que posean la característica de veraces. Desde luego, como aclaró posteriormente el TC, la veracidad de las informaciones no se corresponde con la verdad absoluta de los hechos transmitidos ${ }^{10}$ sino que, por el contrario, el informador, que normalmente será un periodista, quedará amparado por la

6 Posición que fue seguida por un importante sector de la doctrina. A modo de ejemplo, véase DESANTES GUANTER, J.M. y SORIA, C.: Los límites de la información, Asociación de la prensa de Madrid, Madrid, 1991, págs. 20 y ss.

7 No obstante, el propio TC reconoce la enorme dificultad su diferenciación, pues «en los casos reales que la vida ofrece, no siempre es fácil separar la expresión de pensamientos, ideas y opiniones de la estricta comunicación informativa, pues la expresión de pensamientos necesita a menudo apoyarse en la narración de hechos, y a la inversa, la comunicación de hechos o de noticias no se da nunca en un estado químicamente puro y comprende, casi siempre, algún elemento valorativo o, dicho de otro modo, una vocación a la formación de una opinión». Véase STC 6/1988, de 21 de enero, FJ $5^{\circ}$.

8 En este sentido, entre otras, véanse STC 6/1988, de 21 de enero, FJ 5; STC 232/2002, de 9 de diciembre, FJ $2^{\circ}$, y STC 160/2003, de 15 de septiembre, FJ $3^{\circ}$.

9 En la doctrina existen importantes estudios sobre los criterios para distinguir entre ambas libertades en el caso concreto, a modo de ejemplo, entre otros, véase MUÑOZ LORENTE, J.: La libertad de información y el derecho al honor en el Código Penal de 1995, Valencia, Tirant lo Blanch, págs. 120 y ss. 
libertad de información si demuestra que, antes de la difusión de la información, ha comprobado y contrastado diligentemente la misma y tiene la convicción personal de que se corresponde con la realidad ${ }^{11}$. La comprobación de la veracidad se realizará teniendo en cuenta las circunstancias del caso concreto ${ }^{12}$. No obstante, el TC sí exige la veracidad objetiva en el denominado reportaje neutral, que se produce cuando un medio de comunicación reproduce lo que un tercero ha dicho, limitándose a dar cuenta de las declaraciones, sin asumir el mensaje $\mathrm{e}^{13}$.

El proceso informativo requiere de tres fases, a saber, la recogida de datos, la elaboración de esos datos para crear esa información y su difusión ${ }^{14}$. Parece lógico que el derecho a comunicar libremente información veraz ampare al sujeto emisor de la información en todas y cada una de esas fases ${ }^{15}$. Ni el texto constitucional ni su legislación de desarrollo aluden a los concretos métodos de investigación ${ }^{16}$. Al respecto, el TEDH aclaró que corresponde a los profesionales de la información la elección de la concreta téc-

10 Se trata del criterio de veracidad objetivo, que ha sido desechado por la mayoría de la doctrina. No obstante, hay autores que defienden el citado criterio, a modo de ejemplo, véanse DESANTES GUANTER, J.M. y SORIA, C.: Los límites de la información, ob. cit., pág. 49 y ss; DE DOMINGO PÉREZ, T.: ¿Conflictos entre derechos fundamentales?: un análisis desde las relaciones entre los derechos a la libre expresión e información y los derechos al honor y a la intimidad, Madrid, CEPC, pág. 128 y ss.

11 Sobre la cuestión, la STC 68/2008, de 23 de junio, FJ $3^{\circ}$, sintetiza la posición del tribunal de la siguiente manera: «En la doctrina de este Tribunal sobre la veracidad se parte de que este requisito no va dirigido a la exigencia de una rigurosa y total exactitud en el contenido de la información, sino a negar la protección constitucional a los que trasmiten como hechos verdaderos, bien simples rumores, carentes de toda constatación, bien meras invenciones o insinuaciones sin comprobar su realidad mediante las oportunas averiguaciones propias de un profesional diligente; todo ello sin perjuicio de que su total exactitud pueda ser controvertida o se incurra en errores circunstanciales que no afecten a la esencia de lo informado. La razón de ello se encuentra en que, como hemos señalado en muchas ocasiones, cuando la Constitución requiere que la información sea «veraz» no es que prive de protección a las informaciones que puedan resultar erróneas sino que establece un deber de diligencia sobre el informador a quien se le puede y debe exigir que lo que transmite como «hechos» haya sido objeto de previo contraste con datos objetivos. De este modo, el requisito de la veracidad deberá entenderse cumplido en aquellos casos en los que el informador haya realizado con carácter previo a la difusión de la noticia una labor de averiguación de los hechos sobre los que versa la información y que la referida indagación la haya efectuado con la diligencia que es exigible a un profesional de la información».

Sostener que el concepto de veracidad se corresponde con la absoluta correspondencia entre lo informado y lo realmente sucedido generaría un importante efecto de desaliento en la actividad de los periodistas que, por miedo a cometer errores, se abstendrán de informar sobre muchas cuestiones y, por ende, muchas cuestiones esenciales para la formación de la opinión pública no saldrían a la luz pública. En este sentido, véase STC 171/1990, de 12 de noviembre, FJ $8^{\circ}$.

12 El TC, a la hora de comprobar la veracidad de una concreta información, ha acudido, entre otros, a los siguientes criterios: la concreta fuente generadora de la información; las consecuencias que la información puede tener en la persona afectada; si el difusor de la información es o no profesional de la información; las características concretas medio de difusión, etc. Sobre la cuestión, entre otros, véase SÁNCHEZ FERRIZ, R.: Delimitación de las libertades informativas, Valencia, Tirant lo Blanch, 2004, págs. 168 y ss.

13 Véase STC 158/2003, de 15 de septiembre, FJ $7^{\circ}$. Sobre la cuestión, téngase en cuenta que la jurisprudencia ha desestimado la aplicación de la doctrina del reportaje neutral a la cámara oculta, como consecuencia de que el medio de comunicación provoca la noticia. A modo de ejemplo, véanse STC 76/2002, de 8 de abril, FJ14; STS 506/2009, de 6 de julio, FJ 2; STS 1233/2009, de 16 de enero, FJ $4^{\circ}$ y STS 336/2010, de 20 de mayo, $\mathrm{FJ}^{\circ}$.

14 Véase URÍAS, J.: Lecciones de Derecho de la Información, Madrid, Tecnos, 2009, pág. 77.

15 Sin embargo, el artículo 20.1 d) de la CE no alude expresamente a que la libertad de información proteja la facultad de obtener o investigar informaciones. Se trata de una omisión del constituyente que debe ser 
nica de investigación ${ }^{17}$. Ahora bien, si bien los «métodos de la información objetiva y ponderada varían considerablemente», no existe una total discrecionalidad en su elección, pues la prensa «no debe traspasar los límites que establece, entre otras, la protección de los derechos de los demás, incluidos los requisitos de obrar de buena fe y sobre la base de unos hechos veraces y ofrecer una información fiable y precisa de acuerdo con la ética periodística» ${ }^{18}$.

\section{LOS DERECHOS A LA INTIMIDAD PERSONAL Y FAMILIAR Y A LA PROPIA IMAGEN}

\section{II.1. DeLIMITACiÓN DEL DERECHO A LA INTIMIDAD PERSONAL Y FAMILIAR}

Resulta sumamente complejo delimitar de manera clara e inequívoca el derecho a la intimidad ${ }^{19}$. La doctrina ha utilizado fundamentalmente dos criterios para su definición $^{20}$. Así, un importante sector doctrinal sostiene un criterio objetivo o material del derecho a la intimidad, que se identifica, como alude el diccionario de la RAE, con la zona «espiritual íntima y reservada de una persona o grupo, especialmente de una familia». Como se observa, la intimidad se define por contraposición a lo público, esto es, con el núcleo de cuestiones o relaciones privadas que el sujeto pretende preservar del conocimiento ajeno. La citada concepción ha sido desarrollada fundamentalmente por la doctrina alemana mediante la teoría de las esferas ${ }^{21}$. El TC ha acogido en algunos de sus

colmada vía interpretativa acudiendo al criterio establecido en el artículo 10.2 de la CE en la medida que tanto el artículo 19 de la DUDH como el artículo 19.2 del PIDCP incluyen dentro del contenido de la libertad de información la facultad de investigar. Además, si como se ha dicho, la veracidad de las noticias no se identifica con la absoluta correspondencia de los hechos transmitidos con la realidad, sino que, también protege aquellas informaciones erróneas o equivocadas, siempre que el informador realice una diligente búsqueda de la verdad que asegure la seriedad del esfuerzo informativo; parece claro que resulta absolutamente necesario para cumplir este requisito que el transmisor de la información tenga asegurada la capacidad de investigar y contrastar las informaciones. Por si hubiera alguna duda, el TC ha mantenido en varios pronunciamientos que el contenido del derecho a comunicar libremente información veraz comprende el proceso comunicativo completo, esto es, desde la obtención y elaboración de la noticia hasta su difusión pública. A modo de ejemplo, entre otras, véanse STC 6/1981, de 16 de marzo, FJ 5; STC 171/1991, de 12 de noviembre, FJ 9º y STC 56/2004, de 19 de abril, $\mathrm{FJ} 4^{\circ}$.

16 Sobre el derecho a obtener información, entre otros, véanse MEDINA GUERRERO, M.: La protección constitucional de la intimidad frente a los medios de comunicación, ob.cit., págs. 70 y ss; ROSADO IGLESIAS, G.: «El estatuto jurídico de los profesionales de la información» en TORRES DEL MORAL, A. (Dir.): Libertades informativas, Madrid, Colex, 2009, pág. 362 y ss. y URÍAS, J.: Lecciones de Derecho de la Información, ob. cit., págs. 78 y ss.

17 Entre otras, véanse STEDH 36/1994, de 23 de septiembre, «caso Jersild», Párr. 47 y STEDH 45/2011, de 10 de mayo, «caso Mosley», Párr. 113.

18 Véase STEDH 45/2011, de 10 de mayo, «caso Mosley», Párr. 113.

19 De hecho, el texto constitucional se limita a enunciar su reconocimiento en el artículo $18 \mathrm{CE}$, y el artículo 20.4 CE alude a que también se trata de un límite a las libertades de comunicación pública. De la legislación de desarrollo del citado derecho tampoco se puede obtener una definición del derecho a la intimidad. 
pronunciamientos el citado criterio objetivo o material ${ }^{22}$. Probablemente, el principal problema de esta concepción de la intimidad reside en la dificultad de determinar su ámbito de protección de manera exacta y, por lo tanto, la necesidad de analizar caso por caso.

Otro importante sector de la doctrina entiende que el derecho a la intimidad se corresponde con el derecho a la autodeterminación informativa. Se trata de una concepción, muy influenciada por las tesis de WARREN y BRANDEIS ${ }^{23}$, según la cual la intimidad determina un grado de control sobre la difusión de la información personal que accede al conocimiento público. Concretamente los citados autores aluden a que el common law garantiza a cada persona el derecho a decidir hasta qué punto pueden ser comunicados a otros sus pensamientos, sentimientos, etc ${ }^{24}$. Desde esta perspectiva, el sujeto titular del derecho puede determinar qué aspectos de su vida privada pueden ser de conocimiento público y cuáles no. Otorga, en consecuencia, la facultad de controlar el flujo informativo que sobre uno mismo accede al conocimiento público. Por tanto, la conducta del titular del derecho cobra especial relevancia, en el sentido de que si divulga públicamente una cuestión de su intimidad o consiente que un tercero lo realice, parece claro que luego debe soportar que los medios de comunicación den cuenta e informen de ello. Al igual que en el caso anterior, el TC ha utilizado este criterio en varios de sus pronunciamien$\operatorname{tos}^{25}$. No obstante, como sucede con el criterio objetivo, se está ante un criterio que po-

20 Lo cierto es que también existen otros criterios como, por ejemplo, la teoría del mosaico. Véase MADRID CONESA, F.: Derecho a la intimidad, informática y Estado de Derecho, Valencia, Universidad de Valencia, 1984, pág. 45.

21 Como sintetiza MEDINA GUERRERO, desde la perspectiva de la citada doctrina habría que distinguir diferentes esferas dotadas de diversos niveles de protección, de tal forma que cuanto más se acerque la información al núcleo duro de lo materialmente íntimo, mayor interés público se debe exigir a dicha información para que su difusión pública sea constitucionalmente legítima. Concretamente se definen tres esferas: la esfera íntima, la esfera personal y la esfera social. La primera esfera, esto es, la esfera íntima, protege frente a aquellas informaciones que inciden en el ámbito vital interno de las personas como, por ejemplo, la vida sexual, el mundo sentimental, datos relativos al ser físico como la enfermedad, etc. En principio, las cuestiones comprendidas en dicha esfera gozan de la máxima protección y sólo supuestos muy excepcionales de relevancia pública podrían justificar una intromisión. Por su parte, la esfera privada comprende cuestiones que afectan a la vida doméstica y al círculo de relaciones personales. Ejemplos de asuntos incluidos dentro de esta esfera son la situación familiar, las creencias religiosas, etc. La protección de esta esfera es menor que la anterior y, por ende, el interés público que podría justificar su divulgación debe ser inferior. Por último, la esfera social hace referencia a las relaciones de las personas en su ámbito social. En principio, hay una mayor posibilidad de divulgación pública, siempre que no se divulguen datos falsos o atentatorios contra el derecho al honor. Véase MEDINA GUERRERO, M.: La protección constitucional de la intimidad frente a los medios de comunicación, ob. cit., págs. 13 y ss.

22 Así, por ejemplo, la STC 185/2002, de 14 de octubre, FJ $3^{\circ}$, mantiene que la intimidad: «tiene por objeto garantizar al individuo un ámbito reservado de su vida, vinculado con el respeto de su dignidad como persona (artículo 10.1 CE), frente a la acción y el conocimiento de los demás, sean éstos poderes públicos o simples particulares. (...) Lo que el artículo 18.1 CE garantiza es, pues, el secreto sobre nuestra propia esfera de vida personal y, por tanto, veda que sean los terceros, particulares o poderes públicos, quienes decidan cuáles son los contornos de nuestra vida privada».

23 Sobre el origen e influencia de la citada concepción del derecho a la intimidad en la jurisprudencia norteamericana, entre otros, véanse REBOLLO DELGADO, L.: «El derecho a la intimidad», en TORRES DEL MORAL A: Libertades informativas, Madrid, Colex, 2009, pág. 257 y ss, y NIEVES SALDAÑA, M.: «El de- 
see importantes dosis de indefinición, pues no permite determinar de manera exacta e indubitada el contenido de la intimidad.

Como consecuencia de las insuficiencias de los anteriores criterios, son varios los autores que abogan por un concepto del derecho a la intimidad que aglutine a ambos con$\operatorname{ceptos}^{26}$, criterio que parece que ha sido acogido finalmente por el $\mathrm{TC}^{27}$.

Por último, se aludirá a que el ámbito de protección del derecho a la intimidad, no sólo se extiende, como expresamente alude el artículo 18 de la CE, a la intimidad personal y familiar, sino que, asimismo, comprende aspectos relacionados con el trabajo o la profesión, pues en los mismos se desarrollan relaciones interpersonales o actuaciones que pueden constituir manifestación de la vida privada ${ }^{28}$.

\section{II.2. Delimitación DEL DERECHO A LA PROPIA IMAGEN}

Si bien inicialmente un importante sector de la doctrina y la jurisprudencia del TC destacaron que se trata de un derecho que forma parte del derecho a la intimidad ${ }^{29}$, lo cierto es que es hoy, pese a que en la realidad práctica resulta sumamente difícil su

recho a la privacidad en los Estados Unidos: aproximación diacrónica a los intereses constitucionales en juego, TRC, núm. 28, 2011, págs. 282 y ss.

24 Véase WARREN, S. y BRANDEIS, L.: El derecho a la intimidad, Civitas, Madrid, 1995, pág. 31.

25 Así, por ejemplo, en la STC 134/1999, de 15 de julio, FJ 5º, afirmó que: «el artículo 18 CE no garantiza una «intimidad» determinada, sino el derecho a poseerla, a tener vida privada, disponiendo de un poder de control sobre la publicidad de la información relativa a la persona y su familia, con independencia del contenido de aquello que se desea mantener al abrigo del conocimiento público. Lo que el artículo 18.1 garantiza es un derecho al secreto, a ser desconocido, a que los demás no sepan qué somos o lo que hacemos, vedando que terceros, sean particulares o poderes públicos, decidan cuáles sean los lindes de nuestra vida privada pudiendo cada persona reservarse un espacio resguardado de la curiosidad ajena, sea cual sea lo contenido en ese espacio».

26 En este sentido, entre otros, véanse REBOLLO DELGADO, L.: El derecho fundamental a la intimidad, Madrid, Dykinson, 2000, pág. 93, CARRILLO LÓPEZ, M.: El derecho a no ser molestado. Información y vida privada, Cizur Menor, Thomson-Aranzadi, 2003, págs. 50 y ss.

27 Así, en la STC 115/2000, de 5 de mayo, FJ $4^{\circ}$, afirma lo siguiente: «el derecho fundamental a la intimidad reconocido por el artículo 18.1 CE tiene por objeto garantizar al individuo un ámbito reservado de su vida, vinculado con el respeto de su dignidad como persona (artículo 10.1 CE), frente a la acción y el conocimiento de los demás, sean éstos poderes públicos o simples particulares. De suerte que el derecho a la intimidad atribuye a su titular el poder de resguardar ese ámbito reservado, no sólo personal sino también familiar (...), frente a la divulgación del mismo por terceros y una publicidad no querida. No garantiza una intimidad determinada sino el derecho a poseerla, disponiendo a este fin de un poder jurídico sobre la publicidad de la información relativa al círculo reservado de su persona y su familia, con independencia del contenido de aquello que se desea mantener al abrigo del conocimiento público. Lo que el artículo 18.1 CE garantiza es, pues, el secreto sobre nuestra propia esfera de intimidad y, por tanto, veda que sean los terceros, particulares o poderes públicos, quienes decidan cuáles son los lindes de nuestra vida privada. Corresponde, pues, a cada individuo reservar un espacio, más o menos amplio según su voluntad, que quede resguardado de la curiosidad ajena, sea cual sea lo contenido en ese espacio. Y, en correspondencia, puede excluir que los demás, esto es, las personas que de uno u otro modo han tenido acceso a tal espacio, den a conocer extremos relativos a su esfera de intimidad o prohibir su difusión no consentida». En sentido similar, entre otras, véanse STC 83/2002, de 22 de abril, FJ 5; STC 121/2002, de 20 de mayo, FJ $2^{\circ}$ y STC 127/2003, de 30 de junio, FJ $7^{\circ}$.

28 A modo de ejemplo, véase STEDH 77/1992, de 16 de diciembre, «caso Niemietz», párr. 29. 
total deslinde, es prácticamente unánime la idea de que el derecho a la propia imagen es un derecho fundamental autónomo y, por ende, dotado de sustantividad específica ${ }^{30}$. El derecho a la propia imagen no se identifica con la imagen o reputación social, que estaría protegida por el derecho al honor, sino que se refiere a la imagen de la persona, esto es, a la representación gráfica de la figura humana en sentido estricto ${ }^{31}$. Por tanto, este derecho protege frente a la captación o reproducción no consentida de los rasgos físicos o características externas de la persona. Asimismo resulta necesario que la reproducción de la imagen permita la identificación del sujeto ${ }^{32}$. Sensu contrario, si no resulta posible identificar a la persona, la imagen resulta irrelevante a los efectos del derecho. Por tanto, «únicamente cuando concurre la percepción de los particulares rasgos individualizadores e identificadores de una imagen humana, ésta adquiere entidad como representación en forma visible de la figura de un hombre concreto y, consecuentemente, sólo entonces se puede hablar de la imagen como objeto de un derecho $^{33} »$.

El derecho a la propia imagen tiene una doble dimensión. De un lado, en su faceta positiva, se concreta en la facultad de cada persona para obtener, reproducir o publicar su propia imagen. De otro, en su faceta negativa, consiste en la facultad de impedir la captación, reproducción o publicación de la propia imagen por parte de un tercero no autorizado, sea cual sea la finalidad — informativa, comercial, científica, cultural, etc.perseguida por quien la capta o la difunde ${ }^{34}$. Al igual que el derecho a la intimidad, el derecho a la propia imagen queda delimitado por la propia voluntad de su titular. En otras palabras, «el derecho a la propia imagen proporciona a su titular la potestad de autodeterminación sobre el flujo de información gráfica generado por sí mismo, a fin de controlar su reproducción y difusión ${ }^{35} »$.

29 Desde un perspectiva doctrinal, a modo de ejemplo, véase SOLOZÁBAL ECHAVARRÍA, J.J.: «La libertad de expresión y derecho a la intimidad de los personajes públicos no políticos», Anuario de Derecho Constitucional y Parlamentario, núm. 2, 1990, pág. 51 y ss.

30 A modo de ejemplo, véase STC 83/2002, de 22 de abril, FJ 4º . Cuestión distinta a la afirmación hecha arriba es que mediante una intromisión ilegítima en el derecho a la propia imagen, además se vulnere el derecho al honor o la intimidad, pues puede darse la circunstancia de que la imagen revele la vida privada de una persona o que mediante la imagen también se denigre o ridiculice a una persona. En tal caso, dichos efectos se deberán analizar desde el punto de vista del derecho a la intimidad o al honor. Véase ATC 176/2007, de 1 de marzo, FJ $2^{\circ}$.

31 Como aclara PASCUAL MEDRANO, el derecho a la propia imagen comprende la imagen en sentido estricto, esto es, la representación gráfica de la vida humana, pero también la voz y el nombre de las personas, si bien el contenido del derecho difiere en ambos en cada caso. «Mientras que el titular está facultado para decidir sobre la captación, reproducción o publicación de su propia imagen (...), respecto al nombre y a la voz, únicamente dispone de la facultad de decidir sobre su utilización comercial. La voz y el nombre se protegen así sólo en cuanto se utilicen con fines comerciales, publicitarios o similares. Véase PASCUAL MEDRANO, A.: El derecho fundamental a la propia imagen. Fundamento, contenido, titularidad y límites, Cizur Menor, Thomson-Aranzadi, 2003, págs. 62 y ss.

32 Véase STC 127/2003, de 30 de junio, FJ $6^{\circ}$.

33 Véase AZURMENDI ADARRAGA, A.: El derecho a la propia imagen: su identidad y aproximación al derecho a la información, Madrid, Cívitas, 1999, pág. 28. 


\section{LA PONDERACIÓN COMO INSTRUMENTO PARA LA RESOLUCIÓN DE CONFLICTOS ENTRE LOS DERECHOS FUNDAMENTALES}

La utilización por parte del TC de la técnica de la ponderación para resolver los conflictos entre las libertades de comunicación pública y los derechos de la personalidad del artículo 18 de la CE, supone la aceptación de la denominada teoría externa de la limitación de los derechos fundamentales, hoy mayoritaria entre la doctrina ${ }^{36}$. Desde esta perspectiva, todas las limitaciones del derecho fundamental, bien sean expresas o inmanentes, derivadas de la protección de otro derecho fundamental o bien constitucionalmente protegido, provienen del exterior del derecho ${ }^{37}$. En consecuencia, las limitaciones de los derechos fundamentales no configuran el supuesto de hecho del derecho, no lo delimitan, sino que, por el contrario, operan extrínsecamente sobre el derecho previamente delimitado ${ }^{38}$.

Desde la perspectiva de esta doctrina, para conocer si una conducta queda finalmente amparada por un derecho fundamental se deben dar varios pasos. En primer lugar, se entenderán protegidas por el derecho fundamental todas aquellas facultades directamente relacionadas potencialmente con el derecho fundamental, esto es, se realizará una interpretación lo más amplia posible del mismo de acuerdo a su delimitación constitucional ${ }^{39}$, lo que a efectos del presente estudio incluiría la utilización de la cámara oculta. La citada operación se realizará sin comprobar si la conducta puede dañar el contenido de otro derecho fundamental o bien constitucionalmente protegido. De esta forma, se halla el contenido inicialmente protegido por el derecho fundamental. En segundo lugar, se aplicarán los límites del derecho fundamental derivados de la protección de otros derechos o bienes constitucionalmente protegidos para obtener como resultado el contenido definitivamente amparado por el derecho fundamental.

34 Véase STC 83/2002, de 22 de abril, FJ $4^{\circ}$.

35 Véase CARRILLO, M.: «El derecho a la propia imagen como derecho fundamental», Revista jurídica de Asturias, núm. 18, 1994, pág. 18.

36 En este sentido, entre otros, véanse AGUIAR DE LUQUE, L.: «Los límites de los derechos fundamentales», Revista del Centro de Estudios Constitucionales, núm. 14, 1993, págs. 9 y ss; BACIGALUPO SEGGESE en BACIGALUPO SAGGESE, M. y VELASCO CABALLERO, F.: « «Límites inmanentes» de los derechos fundamentales y reserva de ley (Dos puntos de vista a propósito de la sentencia de la Sala de lo Contencioso-Administrativo del Tribunal Supremo de 15 de julio de 1993)», Revista española de Derecho Administrativo, núm. 85, 1995, págs. 117 y ss; GAVARA DE CARA, J.C.: Derechos fundamentales y desarrollo legislativo. La garantía del núcleo esencial de los derechos fundamentales en la Ley Fundamental de Bonn, Madrid, Centro de estudios políticos y Constitucionales, Madrid, pág. 171 y ss; MEDINA GUERRERO M.: La vinculación negativa del legislador a los derechos fundamentales, Aravaca, MacGraw Hill, 1996, págs. 61 y ss.

37 Véase STC 12/2012, de 30 de enero, FJ $6^{\circ}$.

38 En sentido contrario al defendido, véanse DE DOMINGO PÉREZ, T.: ¿Conflictos entre derechos fundamentales?, un análisis desde las relaciones entre los derechos a la libre expresión e información y los derechos al honor y a la intimidad, ob.cit., págs. 185 y ss; MUÑOZ LORENTE, J.: La libertad de información y el derecho al honor en el Código Penal de 1995, ob.cit., págs. 132 y ss.

39 Véase PRIETO SANCHÍS, L.: «Observaciones sobre las antinomias y el criterio de ponderación», Cuadernos de derecho público, núm. 11, 2000, pág. 18. 
La limitación legislativa de los derechos no resuelve definitivamente el conflicto entre los derechos fundamentales o de éstos con otros bienes constitucionalmente protegi$\operatorname{dos}^{40}$. Se trata de una ponderación en abstracto que debe ser examinada dadas las circunstancias del caso concreto por los Tribunales. Cuando los órganos judiciales aprecien la posible existencia de una conducta integrable en una contravención de un derecho fundamental o de los preceptos que lo desarrollan (penales o civiles), tiene la obligación de efectuar un juicio ponderativo que les permita dilucidar, vistas las circunstancias del caso, cuál de los dos intereses en conflicto debe prevalecer en el caso concreto ${ }^{41}$. Como se observa, la ponderación se identifica con el principio de proporcionalidad. Desde esta perspectiva, como afirma el TC, «la intromisión en los derechos fundamentales de terceros resultante del ejercicio de la libertad de información sólo será legítima en la medida en que la afectación de dichos derechos resulte adecuada, necesaria y proporcionada para la realización constitucional del derecho a la libertad de información ${ }^{42}{ }$.

De la jurisprudencia del TC cabe inferir que existe una jerarquía flexible o preferencia meramente apriorística de las libertades comunicativas respecto de los derechos al honor, la intimidad y la propia imagen con distintos matices ${ }^{43}$. Preferencia relativa que se deduce

40 De ahí que ni la LO 1/1982, de 5 de mayo, de protección civil del derecho al honor, a la intimidad personal y familiar y a la propia imagen, ni los distintos tipos penales que protegen los citados derechos resuelven definitivamente los conflictos entre los derechos de la personalidad y las libertades de comunicación pública.

41 Así, por ejemplo, la STC 104/1986, de 17 de julio, FJ 5º, afirma que: «cuando del ejercicio de la libertad de opinión (artículo 20.1.a) y/o del de la libertad de comunicar información por cualquier medio de difusión (artículo 20.1.d) resulte afectado el derecho al honor de alguien, nos encontraremos ante un conflicto de derechos ambos de rango fundamental, lo que significa que no necesariamente y en todo caso tal afectación del derecho al honor haya de prevalecer respecto al ejercicio que se haya hecho de aquellas libertades, ni tampoco siempre hayan de ser éstas consideradas como prevalentes, sino que se impone una necesaria y casuística ponderación entre uno y otras». En este sentido, el TEDH sostiene una metodología bastante similar. Así, como sintetiza CATALÁ I BAS, «la metodología a seguir ha sido la siguiente: en primer lugar, fijar el concreto derecho ejercido y el fin que ha perseguido la injerencia y que ha entrado en conflicto con el anterior (seguridad pública, defensa del orden, reputación ajena, derechos ajenos ...). A partir de allí se lleva a cabo la ponderación teniendo en cuenta todas las circunstancias del caso, siendo elementos de peso, que se trate de un asunto de interés público y/o el carácter de personaje público (si la libertad ejercida era la de información), la existencia de una base fáctica en las críticas, la no utilización gratuita de términos injuriosos, la difusión del mensaje o la necesidad o proporción de la injerencia». Véase CATALÁ I BAS.: A.H.: Libertad de expresión e información. La jurisprudencia del Tribunal Europeo de los Derechos Humanos y su recepión por el Tribunal Constitucional, hacia un derecho europeo de los derechos humanos, Valencia, Ediciones Revista General de Derecho, 2001, pág. 411. En general, sobre la libertad de expresión en la jurisprudencia del TEDH, véase SERRANO MAÍLLO, I.: «El derecho a la libertad de expresión en la jurisprudencia del Tribunal Europeo de Derechos Humanos: Dos casos españoles», TRC, núm. 28, 2011, págs. 579 y ss.

42 Véase STC 12/2012, de 30 de enero, FJ $6^{\circ}$.

43 Obsérvese que no se ha utilizado el concepto de libertades preferentes, doctrina acuñada por el TS de los Estados Unidos, pues no resulta aplicable al ordenamiento constitucional español fundamentalmente como consecuencia de que la CE no establece una jerarquía entre los derechos fundamentales y, por ende, se debe realizar una interpretación de los derechos integrada y armónica.

En cualquier caso, como afirma SOLOZÁBAL ECHAVARRÍA «la resolución de los conflictos entre los derechos constitucionales ha se establecerse en cada caso - lo que no quiere decir que no pueda haber estándares, establecidos básicamente por el TC, aplicables en principio para los supuestos de conflictos determinados caracteres, pero como pauta de medio alcance en su nivel de generalización-como consecuencia de una ponderación que, aunque pueda establecer la prevalencia de ese determinado supuesto de un derecho fundamental sobre otro, en razón a las específicas circunstancias de cada caso debe afirmarse sin negar la exigencia del derecho no preferente y procurando, en la medida de lo posible, la concordancia práctica entre ambos derechos». 
de la dimensión institucional de las libertades de expresión e información, es decir, del papel que desempeñan las citadas libertades en el Estado social y democrático de Derecho, esto es, en cuanto que contribuyen a la formación de la opinión pública. Concretamente, en el conflicto entre la libertad de información y los derechos a la intimidad personal y familiar y a la propia imagen, prevalecerá la primera si la información es veraz, esto es, si se ejerce de acuerdo a su delimitación constitucional y, además, las informaciones versan sobre cuestiones de relevancia o interés público. Eso sí, el TC mantiene que la libertad de información «solamente puede legitimar las intromisiones en otros derechos que guarden congruencia» con la formación de la opinión pública y no, por el contrario, si se ejercita de modo desmesurado o exorbitante en relación a su papel en el Estado democrático ${ }^{44}$, con lo que está haciendo una clara alusión a la aplicación del principio de proporcionalidad.

\section{APLICACIÓN DE LOS CRITERIOS DE PONDERACIÓN A LOS REPORTAJES REALIZADOS MEDIANTE CÁMARA OCULTA}

Sentadas las anteriores premisas, se analizará la STC 12/2012 que puede ser calificada como el leading case en la materia ${ }^{45}$. El caso trata de una periodista que acudió a la consulta de una esteticista y naturista, haciéndose pasar por una paciente, por lo que fue atendida por ésta en la parte de su vivienda destinada a la consulta, ocasión que fue utilizada por la primera para grabar la voz y la imagen de la segunda mediante una cámara oculta. La grabación se emitió en un programa de una televisión autonómica. Además de emitirse la citada grabación, también se desarrolló una tertulia sobre el intrusismo en el mundo de la salud. Durante la citada tertulia, los intervinientes criticaron a la naturista, cuya imagen aparecía en un ángulo de la pantalla, con evidentes fines de identificación y, asimismo, pusieron de manifiesto que ésta había sido condenada tres años atrás por un delito de intrusismo profesional.

\section{IV.1. CÁmARA OCULTA Y DERECHO A LA INTIMIDAD}

La utilización de la cámara oculta afecta e invade, cuanto menos prima facie, el ámbito constitucionalmente protegido por el derecho a la intimidad ${ }^{46}$. En este caso concreto, como consecuencia de que la cámara oculta se utilizó en un despacho profe-

Véase SOLOZÁBAL ECHAVARRÍA, J.J.: «La libertad de expresión y derecho a la intimidad de los personajes públicos no políticos», ob. cit., pág. 57.

44 Véase STC 12/2012, de 30 de enero, FJ $6^{\circ}$.

45 Concretamente su doctrina ha sido ratificada en la STC 24/2012, de 27 de febrero, y la STC 74/2012, de 16 de abril.

46 Como afirma el TC, «la técnica de investigación periodística llamada «cámara oculta» impide que la persona que está siendo gravada pueda ejercer su legítimo poder de exclusión frente a dicha grabación, oponiéndose a su realización y posterior publicación, pues el contexto secreto y clandestino se mantiene hasta el momento mismo de la emisión y difusión televisiva de lo grabado, escenificándose con ello una situación o una conversación que, en origen, responde a la provocación de las periodista interviniente, verdadero motor de la noticia que luego se pretende difundir». Véase STC 12/2012, de 30 de enero, FJ $6^{\circ}$. 
sional, lugar que está específicamente ordenado a asegurar la discreción de lo hablado y donde, además, se tiene una expectativa razonable de no ser escuchado u observado ${ }^{47}$. La invasión de la intimidad se produce no sólo como consecuencia de la captación, grabación o reproducción, sino que la mera colocación de una cámara o cualquier aparato análogo en un momento o lugar en el que se desarrolle la vida privada constituye una injerencia, de no mediar autorización. Consentimiento que, desde la comprensión del derecho a la intimidad como el derecho a la autodeterminación informativa, excluiría su violación. Precisamente, la imposibilidad de obtener el consentimiento de la persona grabada es el principal reproche que realiza el TC sobre la utilización de la cámara oculta ${ }^{48}$.

Pues bien, la STC 12/2012 a la hora de ponderar el conflicto entre la libertad de información y el derecho a la intimidad, en primer lugar, recuerda que, a los efectos de la resolución del conflicto, no resulta decisiva la veracidad de la información, pues si bien ésta es relevante a la hora de valorar eventuales intromisiones en el derecho al honor, la veracidad «no es paliativo sino presupuesto de la lesión de la intimidad». En cuanto al criterio de la relevancia pública del reportaje, el TC considera que no se trata de un criterio significativo para la resolución del caso, pues entiende que la utilización de la cámara oculta «en todo caso» constituye una intromisión ilegítima en el derecho a la intimidad. En definitiva, el TC ha concluido que «lo que está constitucionalmente prohibido es justamente la utilización del método mismo», la cámara oculta.

Son varios los aspectos que llaman la atención de la fundamentación del TC. En primer lugar, si bien parte de la premisa de la necesidad de realizar una ponderación casuística entre los derechos en conflicto, y enuncia los criterios de ponderación que viene utilizando al respecto, posteriormente desecha dichos criterios y acaba afirmando taxativamente que el medio utilizado para obtener la información, esto es, la cámara oculta, en todo caso supone una intromisión ilegítima en el derecho a la intimidad, fundamentalmente como consecuencia de su especial capacidad intrusiva. En segundo lugar, el TC no atiende a determinados aspectos que sí fueron considerados esenciales en la ponderación efectuada por el TS en la previa sentencia objeto de recurso de amparo resuelto por la STC $12 / 2012^{49}$. Y, en tercer lugar, la sentencia no tiene en cuenta, probablemente porque se trata de un pronunciamiento posterior, que el TEDH mantiene que a la hora de

47 Ibidem, FJ 6.

48 Concretamente el TC afirma que «la utilización de un dispositivo oculto de captación de la voz y la imagen se basa en un ardid o engaño que el periodista despliega simulando una identidad oportuna según el contexto, para poder acceder al ámbito reservado de la persona afectada con la finalidad de grabar su comportamiento o actuación desinhibida, provocar sus comentarios y reacciones así como registrar subrepticiamente declaraciones sobre hechos o personas, que no es seguro que hubiera podido lograr si se hubiera presentado con su verdadera identidad y con auténticas intenciones». Ibídem, FJ $6^{\circ}$.

49 Concretamente, el TS tuvo en cuenta las siguientes cuestiones: en primer lugar, que en el reportaje no demostró la fisioterapeuta ejerciera sin titulación. En segundo lugar, tampoco se justificó cual fue la razón de que hubiera sido exclusivamente la concreta persona que fue grabada para dar un ejemplo público de una práctica inadmisible y cuya erradicación motiva un interés social indudable. En tercer lugar, que el material obtenido en la investigación careció de la relevancia necesaria para justificar el sacrificio en el derecho a la intimidad. Y, en cuarto lugar, el método utilizado, esto es, la cámara oculta, no era imprescindible para descubrir la verdad de lo que acontecía en la consulta de la parte actora, pues hubiera bastado con que el periodista entrevistara a los clientes de la misma, para conocer con total fidelidad lo que supo de primera mano mediante la grabación directa. Véase STS 1233/2009, de 16 de enero, FJ 6. 
valorar la utilización del concreto método usado para obtener información, se exige que éste se adecúe a las exigencias de la buena fe y de la ética periodística ${ }^{50}$. Pues bien, a continuación se realizará un análisis sobre las tres cuestiones aludidas por separado.

$1^{\circ}$. En referencia a la desestimación de la relevancia pública como criterio suficiente para que prevalezca la libertad de información, se considera que no puede ser desdeñada de una manera tan taxativa para todos los casos. Desde luego, en el caso examinado por el TC, esto es, la denuncia de prácticas de intrusismo profesional, poseían una relevancia pública relativa o escasa. En este sentido, el interés público de una información no se determina en virtud de que la noticia se difunda a través de un mass media ${ }^{51}$, ni mucho menos por lo que le interesa al público en un determinado momento, esto es, no se corresponde con la mera satisfacción de la curiosidad ajena, como han declarado reiteradamente tanto el propio TC como el $\mathrm{TEDH}^{52}$, pues admitir dicha posibilidad implicaría que las audiencias condicionaran el contenido de la intimidad de los ciudadanos. Ni tan siquiera se puede determinar el interés público de una noticia exclusivamente en razón a que verse sobre una persona de relevancia pública ${ }^{53}$, sino que, el interés público se debe definir exclusivamente en referencia a la materia sobre que la versan los hechos ${ }^{54}$, que se corresponde con aquellos asuntos cuyo conocimiento se pueda pensar razonadamente que contribuyen a hacer posible la participación de los ciudadanos en la vida colectiva ${ }^{55}$. Se trata de un criterio de ponderación que está íntimamente relacionado con la dimensión institucional de las libertades de comunicación pública, es decir, con el papel que desempeñan en la formación de la opinión pública y, por ende, en el funcionamiento del Estado democrático ${ }^{56}$. Desde la perspectiva de la aplicación del principio de proporciona-

50 Véase STEDH de 7 de febrero de 2012, «Caso Springer», Párr. 93.

51 Véase STC 134/1999, de 15 de julio, FJ $8^{\circ}$.

52 Así, por ejemplo, en la STEDH 10/2011, de 18 de enero, «caso Mgn Limited», párr. 143, se afirma lo siguiente: «el Tribunal considera que la publicación de las fotografías y de los artículos en litigio, cuyo único fin era el de satisfacer la curiosidad de cierto público sobre los detalles de la vida privada de un personaje público, no se puede considerar que se contribuya a ningún debate de interés general para la sociedad, pese a la notoriedad del personaje. En tales condiciones, la libertad de expresión requiere una interpretación más restrictiva».

53 En todo caso, sólo son de interés público aquellas informaciones que guarden relación directa con el cargo o profesión que desarrollan en el seno de la sociedad. A modo de ejemplo, véase STC 148/2001, de 27 de junio, FJ $6^{\circ}$.

54 Por ello, en diversas ocasiones el TC, ha admitido que una persona privada puede verse involucrada en hechos de interés público y, por tanto, tenga que soportar una intromisión en sus derechos de la personalidad reconocidos en el artículo 18 de la CE. A modo de ejemplo, entre otras, véase STC 99/2002, de 6 de mayo, FJ $7^{\circ}$.

$55 \mathrm{Al}$ respecto conviene resaltar que no sólo son hechos de interés público aquellos estrictamente relacionados con el autogobierno de los ciudadanos como sostiene la teoría liberal-democrática de la libertad de expresión, sino que se aboga por un concepto más amplio puesto que como establece el artículo 1.1 de la CE España se constituye en un Estado social y democrático de Derecho y, por tanto, son más numerosos las cuestiones (economía, cultura, etc.) donde los poderes públicos pueden intervenir.

56 En sentido similar, el TEDH ha sostenido que, «la libertad de expresión constituye uno de los pilares fundamentales de una sociedad democrática y una de las condiciones básicas para que ésta progrese y para el pleno desarrollo individual». Y es que precisamente, «las elecciones libres y la libertad de expresión, especialmente la libertad del debate político, constituyen los cimientos de todo régimen democrático. Véanse, entre otras, STEDH de 27 de febrero de 2001, «caso Jerusalem», Párr. 32; STEDH de 19 de febrero de 1998, «caso Bowman», Párr. 42, y STEDH de 2 marzo 1987, «caso Mathieu-Mohin y Clerfayt», Párr. 47. 
lidad en sentido estricto al caso en concreto, a mayor sacrificio de un derecho, mayor debe ser la satisfacción de los intereses protegidos por el otro derecho. Pues bien, no toda difusión pública de hechos noticiables goza de igual protección ${ }^{57}$, de tal forma que a mayor contribución de la noticia al funcionamiento del sistema democrático, mayor protección deberá dispensarse a la libertad de información. Y, sensu contrario, a menor contribución a la formación de la opinión pública, menor protección ${ }^{58}$. Por tanto, se considera que el TC debió ponderar materialmente los derechos en conflicto atendiendo a las circunstancias del caso concreto, pues hipotéticamente pueden existir cuestiones de alta relevancia pública que podrían justificar la utilización de la cámara oculta como, por ejemplo, la demostración de la existencia de una red de corrupción política o de irregularidades en las instituciones financieras ${ }^{59}$.

Cabe preguntarse sobre el eventual efecto de desaliento o chilling effect que puede generar la prohibición de la utilización de la cámara oculta para el periodismo de investigación $^{60}$. Al respecto, se debe precisar que no toda utilización de la cámara oculta puede englobarse dentro del auténtico periodismo de investigación ${ }^{61}$. En ocasiones, la cámara oculta es utilizada por la denominada prensa rosa para desvelar hechos como, por ejemplo, las relaciones sentimentales de personajes públicos que carecen relevancia pública o, también, por la prensa sensacionalista al objeto de incrementar el impacto y la espectacularidad de sus reportajes. Además, la utilización de la cámara oculta puede ser el medio más económico y rentable para los mass media, frente al auténtico periodismo de investigación, que, por definición, exige emplear más tiempo y dedicar mayor número de profesionales $^{62}$. En definitiva, a los efectos de los casos analizados por el TC hasta el presente momento, no existe efecto de desaliento. Sin embargo, la prohibición incondicio-

57 A modo de ejemplo, véase STS 264/2012, de 18 de abril, FJ 5².

58 En este sentido, de la jurisprudencia del TEDH se desprende que la función social que desempeñan las libertades de expresión e información en el sistema democrático determina distintos grados de protección, así mientras que el debate político tiene un gran nivel de protección, la publicidad comercial tiene un grado menor, y la difusión de datos sobre la vida privada de un personaje público no contribuye a ningún debate de interés general. Véase STEDH 10/2011, de 18 de enero, «caso MGN limited», Párr. 143. Asimismo, en sentido parecido, véase STEDH 45/2004, 24 de junio, «caso Von Hannover», Párr. 45.

59 De no realizarse materialmente una ponderación, caso por caso, supondría afirmar que el derecho a la intimidad prevalece sobre la libertad de información en todo caso.

60 Véase STEDH 8/1986, de 22 de febrero, «caso Lingens», párr. 44. Sobre el efecto de desaliento en el ejercicio de los derechos fundamentales, véase DE DOMINGO PÉREZ, T.: «La argumentación jurídica en el ámbito de los derechos fundamentales en torno al denominado «chilling effect» o «efecto desaliento», Revista de Estudios Políticos, núm. 122, 2003, págs. 141 y ss.

61 En este sentido, como argumenta MIRANDA ESTRAMPES, no siempre el periodismo de investigación exige la utilización de la cámara oculta, «y no siempre la utilización de la cámara oculta puede calificarse como periodismo de investigación». «La equiparación de la cámara oculta y el periodismo de investigación conlleva una verdadera desnaturalización de este último, simplificando las múltiples facetas y ámbitos de investigación por los que debe discurrir». Véase MIRANDA ESTRAMPES, M.: «Prohibición constitucional de la utilización de las cámaras ocultas en la actividad periodística. ¿Fin del periodismo de investigación?», Diario La Ley, núm. 7839.

62 En este sentido, RAMONET mantiene que el actual contexto de los medios de comunicación ha generado una «limpieza» en sus redacciones como, por ejemplo, la supresión de puestos de corresponsales en el extranjero y, lo que es más grave, la «liquidación programada de géneros que se consideran «demasiados caros» o «no rentables como el periodismo de investigación y los reportajes de campo. Véase RAMONET I.: La explosión del periodismo. De los medios de masas a la masa de medios, Madrid, Clave intelectual, 2011, pág. 35. 
nada de la utilización de la cámara oculta quizá podría tener un efecto de desaliento en el auténtico periodismo de investigación y, por ende, muchas cuestiones necesarias para la participación efectiva de los ciudadanos en los asuntos públicos no accederían al conocimiento de la opinión pública. En cierto modo, se podría decir que quedaría limitado el autogobierno de los ciudadanos.

$2^{\circ}$. Entre otros criterios utilizados por el TS que no fueron valorados en su justa medida por el TC, se destacará la posibilidad de obtener la misma información mediante medios alternativos a la cámara oculta. En los casos analizados hasta el presente momento por el TC, todos ellos relacionados con la prensa sensacionalista, con carácter general, sí existían métodos alternativos menos dañinos para obtener idéntica información como, por ejemplo, la realización de entrevistas a los pacientes atendidos o a los vecinos del inmueble $e^{63}$. La posibilidad de utilizar otros medios alternativos se deberá analizar caso por caso, debiéndose utilizar en todo caso criterios de profesionalidad periodística. Se considera que corresponderá al medio de comunicación demostrar que ha intentado infructuosamente la utilización de otros métodos para obtener la información, antes de acudir al método excepcional de la cámara oculta. Dicha posibilidad se dará en la mayoría de los casos, pero quizá no en todos. Así, por ejemplo, piénsese en el caso de la delincuencia organizada o de grupos extremistas donde el profesional de la información puede incurrir en riesgos para su propia vida ${ }^{64}$. De ahí que se considere que cabe la posibilidad de que en un futuro, exclusivamente para casos muy concretos y específicos, el TC pueda admitir excepcionalmente la utilización de la cámara oculta.

$3^{\circ}$. Según un reciente pronunciamiento del TEDH, entre los criterios de ponderación para resolver el conflicto entre la libertad de información y el derecho a la intimidad, se deberá atender a la forma o método mediante el que se obtuvo la información, a cuyo efecto los periodistas «deberán actuar de buena fe (...) y de acuerdo con la ética periodística» ${ }^{65}$. Por tanto, parece desprenderse que para examinar el caso concreto, entre otras cuestiones, también se deberá acudir a las autorregulaciones que se dotan los medios de comunicación y los códigos deontológicos elaborados por las asociaciones de periodistas. En referencia a la primera cuestión, entre los distintos libros de estilo elaborados por los medios, probablemente una las autorregulaciones más detallada e influyente sobre la utilización de la cámara oculta es la que se contiene en las directrices editoriales de

63 Como cita SUÁREZ VILLEGAS, «la cámara oculta no es una vía complementaria para reforzar el proceso indagatorio, sino un vía excepcional que podría ocasionar una lesión de derechos fundamentales como un efecto colateral del empeño por conocer la verdad que se escurre por los obstáculos puestos por el protagonista.» Véase SUÁREZ VILLEGAS, J.C.: «El debate en torno a la utilización de la cámara oculta como técnica de investigación periodística», Comunicación y sociedad, Vol. 24, núm. 2, 2011, pág. 417.

64 Al citado ejemplo, SUÁREZ VILLEGAS añade otros, como son: «riesgo inmediato para la vida de las personas, abusos permanentes de prácticas que atentan contra la salud, (...) un ejercicio corrupto de la función pública, camuflada bajo prácticas legales que impidan conocerlas a primera vista». Ibídem, pág. 414.

65 Véase STEDH de 7 de febrero de 2012, «Caso Springer», Párr. 93.

66 En cuanto a los libros de estilo en nuestro en España, con carácter general, se puede afirmar que contienen una regulación restrictiva sobre la utilización de la cámara oculta. Así, por ejemplo, el punto 2.6.3 del manual de estilo de RTVE establece lo siguiente: «El uso de cámaras y micrófonos ocultos que impiden que una persona sepa que están siendo grabadas su imagen y sus palabras para su posterior emisión pública sólo está justificado en casos muy especiales, como cuando se intenta demostrar la existencia de prácticas ilegales o delictivas que afectan al interés público. La cámara y el micrófono ocultos son el último recursos para probar una 
la $\mathrm{BBC}^{66}$. Concretamente, las citadas directrices admiten la posibilidad de la utilización de la cámara oculta, si bien se aboga por su utilización restrictiva y condicionada ${ }^{67}$. En concreto, se exige que la utilización de la cámara oculta debe estar justificada por un elevado interés público de lo informado ${ }^{68} \mathrm{y}$, asimismo, debe ser el último recurso, esto es, se deben priorizar otros medios de investigación menos gravosos para los derechos fundamentales ${ }^{69}$. Asimismo, se establece la necesidad de obtener la autorización del consejo de redacción del medio, probablemente al objeto de alcanzar una decisión solidaria entre los editores y el equipo de investigación y de que el medio tenga constancia de la utilización de una técnica informativa que le puede acarrear responsabilidades.

En referencia a los códigos deontológicos de los periodistas, algunos admiten excepcionalmente la utilización de la cámara oculta. Así, por ejemplo, el código deontológico del Sindicato de periodistas de Madrid establece que «en todos los medios, y especialmente los audiovisuales, no podrán ser difundidas imágenes privadas o conversaciones si han sido grabadas sin conocimiento de la persona afectada, excepto que se trate de un hecho delictivo» ${ }^{70}$. Por su parte, el punto 25 del Código Europeo de Deontología del periodismo, aprobado por unanimidad por la Asamblea Parlamentaria del Consejo de Europa, el 1 de julio de 1993, establece que «en el ejercicio del periodismo el fin no justifica los medios por lo que la información deberá ser obtenida a través de medios legales y éticos».

Como se observa, no hay un criterio uniforme, pues en unos casos se opta por su prohibición absoluta, mientras que en otros se aboga por una utilización sumamente restrictiva entre los que, desde luego, no estarían incluidos los casos estudiados hasta el presente momento por el TC. La duda se suscita en referencia a casos límite como los enunciados previamente, pues se considera que la ponderación material que realice el tribunal en el caso concreto puede determinar la prevalencia de la libertad de información,

acusación o denuncia de verdadero interés público». Por su parte, el libro de estilo de Canal Sur y Canal 2 Andalucía establece lo siguiente: «Canal Sur TV y Canal 2 no emitirán imágenes grabadas por medios ilegales o conseguidas mediante cualquier ardid (cámara oculta, suplantación de personalidad, engaño...) Su emisión o los medios para conseguirlas sólo está justificada, con autorización previa de la dirección de informativos, en casos de auténtico interés público pero no para airear intimidades particulares o escándalos intrascendentes de cualquier índole».

67 Las directrices editoriales de la BBC son accesibles en internet a través del siguiente enlace: http://www.bbc.co.uk/spanish/specials/150_valores/pdf/valores_bbc_todo.pdf

68 Según el citado medio de comunicación, si bien no existe una única definición de interés público, son cuestiones de interés público, entre otras, las siguientes: «Revelar o descubrir un crimen. Revelar un comportamiento antisocial importante. Revelar corrupción e injusticias. Descubrir incompetencias o negligencias. Proteger la salud o seguridad de las personas. Alertar a las personas del equívoco al que puede llevar una declaración o acción de un individuo u organización. Revelar información que permita a las personas tomar una decisión más fundamentada sobre temas de relevancia pública».

69 Esta idea se concreta en el sentido de que se afirma que la BBC usará grabaciones oculta como «método de investigación (si no hay otra manera de obtener de forma normal las actitudes o comportamientos en cuestión. Los resultados se deben editar de forma que ofrezcan una muestra respetuosa, exacta y precisa de lo sucedido, consiguiendo posteriormente el consentimiento, o distorsionando los rostros de las personas»

70 Otros códigos son más ambiguos, así, por ejemplo, el artículo 14 del Código deontológico de la Federación de Asociaciones de Periodistas de España afirma que «en el desempeño de sus obligaciones profesionales, el periodista deberá utilizar métodos dignos para obtener la información, lo que excluye los procedimientos ilícitos.» 
pues las informaciones obtenidas como, por ejemplo, el caso de un eurodiputado que, por presión de un determinado lobby, contribuya con su actuación a que se modifique una Directiva comunitaria, son esenciales para que la prensa pueda ejercer su papel de "perro guardián público $^{71} \gg \mathrm{y}$, asimismo, su conocimiento posibilita el ejercicio de la censura social y la participación política de los ciudadanos.

\section{IV.2. CÁmARA OCULTA y DERECHO A LA PROPIA IMAGEN}

Como en el caso anterior, la utilización de la cámara oculta sin el consentimiento del sujeto vulnera, prima facie, el derecho a la propia imagen. Los criterios de ponderación que se deben utilizar para la resolución del conflicto, en cuanto a la necesidad de atender a la relevancia pública de la noticia y a la existencia de otros medios alternativos, son coincidentes con el caso anterior, por lo que puede darse por reproducido lo ya dicho.

No obstante, al objeto de ponderar en futuros casos la utilización de la cámara oculta, se debería atender a si la reproducción y difusión de la imagen en la que el sujeto resulta reconocible directa o indirectamente es absolutamente imprescindible para la finalidad informativa y, por tanto, para la formación de la opinión pública ${ }^{72}$, pues en caso contrario, se deberían emplear «técnicas digitales para difuminar el rostro, la voz o ambos», al objeto de garantizar el anonimato ${ }^{73}$. En otras palabras, si la imagen de un determinado sujeto no resulta necesaria para la satisfacción de los intereses constitucionalmente protegidos por la libertad de información, deberá prevalecer el derecho a la propia imagen. Así, en el caso analizado, no era necesario desvelar la identidad de la esteticista para el objeto de la noticia, que consistió en desvelar el intrusismo profesional en el mundo de la salud ${ }^{74} y$, por tanto, se vulneró dicho derecho fundamental. De no aceptarse esta cautela, se produciría un sacrificio innecesario y desproporcionado en el derecho a la propia imagen. Ahora bien, distintos serían aquellos casos en los que la captación de la imagen sea un elemento imprescindible para la finalidad informativa y para la formación de la opinión pública ${ }^{75}$.

71 Véase STEDH 50/1991, de 26 de noviembre, «caso Sunday Times», párr. 50.

72 Sobre la cuestión, entre otras, véanse STS 506/2009, de 6 de julio, FJ $3^{\circ}$ y STS 336/2010, de 20 de mayo, FJ 2; STS 378/2011, de 6 de junio, FJ $4^{\circ}$; STS 179/2011, de 18 de marzo, FJ $4^{\circ}$.

73 A modo de ejemplo, véase STS 336/2010, de 20 de mayo, FJ $2^{\circ}$.

74 Salvando las distancias entre los casos, en los casos de informaciones sobre delitos tampoco resulta necesario identificar o desvelar la identidad de las víctimas a los efectos de divulgar hechos de relevancia pública.

75 Así, por ejemplo, en la STS 470/2011, de 15 de junio, FJ $4^{\circ}$, se afirma que: «la imagen del demandante (...), personaje público, era un elemento imprescindible para la finalidad informativa, a efectos de poder determinar si efectivamente el demandante tenía o no conocimiento de tales hechos y consintieron o no dicha actuación fraudulenta, que de otro modo no hubiera sido posible». 
TITLE: The use of hidden camera in investigative journalism: Does the end justify the means?

RESUMEN: Los métodos que utilizan algunos periodistas para recabar información generan importantes conflictos. En nuestro país, las técnicas de investigación periodísticas han cobrado interés como consecuencia de que la STC 12/2012 ha determinado la probibición constitucional del uso de la cámara oculta. Se trata de una decisión polémica, pues algunos profesionales de la información consideran que dicho pronunciamiento supone el fin del periodismo de investigación, con los consecuentes efectos negativos para el funcionamiento del sistema democrático.

Si bien se considera que en los casos estudiados por el TC hasta el presente momento deben prevalecer los derechos a la intimidad y a la propia imagen sobre la libertad de información, no se comparte su probibición total, pues pueden existir casos límite que, como consecuencia de la imposibilidad de utilizar otros métodos alternativos para obtener la información y de la gran relevancia pública de lo informado, podrían justificar la utilización de la cámara oculta. De no admitir esta posibilidad, se impediría a la prensa ejercer su papel de "perro guardián público» y, por ende, no serían de conocimiento público muchas cuestiones esenciales para el autogobierno de los ciudadanos.

ABSTRACT: The methods used by some journalists to get information generate important conflicts. Journalistic investigation techniques have gathered interest in our country due to the constitutional probibition of the use of hidden camera in the STC 12/2012. It is a polemic decision, as some professionals of information consider it implies the end of investigative journalism and therefore a negative effect on democratic system's running.

Up to now, in the cases studied at the Constitutional Court, it has been considered that the right to privacy and one's own image should prevail over the freedom of information. Even so, the complete probibition of the bidden camera is not shared as there may be extreme cases in which its use could be justified both due to the impossibility of using other alternative methods as well as to the public relevance of the information. If that possibility was not to be admitted, the press could not practice its role as "public watchdog" and therefore essential matters for the self-government of citizens may not be public.

PAlabras Clave: Cámara oculta, libertad de información, derecho a la intimidad, derecho a la propia imagen.

KEY WORDS: Hidden camera, Freedom of information, right to privacy, right to one's own image.

FECHA DE RECEPCIÓN: 11.06.2012 FECHA DE ACEPTACIÓN: 19.07.2012 